\title{
Isolated duodenal ischemia of unknown etiology: a case report
}

\author{
Elahe Meftah ${ }^{1}$, Narjes Mohammadzadeh ${ }^{2 *}$ (I) and Faeze Salahshour ${ }^{3,4}$
}

\begin{abstract}
Background: Acute abdomen is among the most common presentations observed in clinical practice. The present study describes a patient with isolated duodenal ischemia as an extremely rare etiology of acute abdomen.

Case presentation: A 79-year-old male with acute abdominal pain, nausea, and vomiting presented to the emergency department of our hospital. He was diagnosed with myelodysplastic syndrome 7 years ago, for which he took thalidomide and erythropoietin as the main medications. The prominent findings of the physical examination were hypotension, tachycardia, fever, mild hypoxemia, and epigastric and right upper quadrant tenderness of the abdomen. Except for mildly increased creatinine and lipase, other laboratory findings were in concordance with myelodysplastic syndrome. Due to the patient's oliguria, the computed tomography (CT) scan was performed without contrast, which, together with the ultrasonography, raised the clinical impression of acute pancreatitis. The patient's hypotension was refractive to supportive treatment, resulting in progressive deterioration of the clinical condition. A later contrast-enhanced CT scan suggested microvascular ischemia of the duodenum. An emergent Whipple's procedure was planned initially, which was later switched to a damage control surgery due to the patient's cardiac arrest during the surgery. Despite all the supportive therapy provided at the intensive care unit, the patient expired of a cardiac arrest which occurred two hours after the termination of the surgery.
\end{abstract}

Conclusions: The high rate of mortality in duodenal necrosis necessitates emergent diagnosis and proper management. When other common etiologies are ruled out, clinicians should consider duodenal pathology as a potential cause of acute abdomen.

Keywords: Duodenal ischemia, Duodenal necrosis, Myelodysplastic syndrome, Case report

\section{Background}

Duodenal ischemia is one of the most challenging and rarest surgical conditions. This condition may manifest with acute abdomen, one of the most common presentations observed in clinical practice. The literature on this subject is scant and mainly limited to a few published case reports [1-5]. Here we describe an elderly patient with duodenal necrosis of unknown origin who presented to the emergency ward of a tertiary referral hospital.

\footnotetext{
*Correspondence: nmohamadzadeh@sina.tums.ac.ir

${ }^{2}$ Department of Surgery, Imam Khomeini Hospital Complex, Tehran

University of Medical Sciences, Tehran, Iran

Full list of author information is available at the end of the article
}

\section{Case presentation}

The patient was a 79-year-old Caucasian male with a 7-year history of myelodysplastic syndrome (MDS) and a complaint of abdominal pain. The pain started in the evening of the day before and was accompanied by fever, oral intolerance, nausea, and vomiting. He did not complain of bowel habit changes, although he had a history of chronic constipation. Past medical and surgical history was positive for MDS and cholecystectomy. MDS was controlled with daily thalidomide, deferasirox, dimethicone, pantoprazole, gabapentin, vitamin B12, and folic acid. He also took erythropoietin and rivaroxaban three times a week and filgrastim every fifth day. The 
family history and habitual history of the patient were unremarkable.

The patient was awake and oriented on admission, yet he was ill, dehydrated, and mildly agitated. He had blood pressure $95 / 60 \mathrm{mmHg}$, pulse rate $105 / \mathrm{min}$, respiratory rate $17 / \mathrm{min}$, Temperature $37.9{ }^{\circ} \mathrm{C}$, and $\mathrm{O}_{2}$ Saturation $90 \%$ on ambient air. Tenderness of the epigastrium and right upper quadrant of the abdomen was noted, without abdominal distension, rebound tenderness, or guarding. Laboratory results were as mentioned in Table 1 . The patient's electrocardiogram was unremarkable.

Plain thoracic and abdominopelvic radiographs were normal. In abdominopelvic ultrasonography, mild fluid in subhepatic and inflamed echogenic fat in the upper abdomen and around the pancreas was found, along with duodenal wall thickening. With the impression of pancreatitis, intravenous Ciprofloxacin, Metronidazole, Ondansetron, normal saline, and one unit of packed red blood cells were administered. As the patient did not have a proper urinary output $(200 \mathrm{ml}$ since urinary catheterization), the computed tomography (CT) scan was performed without intravenous contrast. The abdominopelvic CT scan demonstrated edematous wall thickening of the entire duodenum with water halo and significant adjacent fat stranding and swelling of the pancreas. Pancreatitis was a potential etiology of secondary duodenal wall thickening [5]. However, observing the

Table 1 Laboratory results of the patient

\begin{tabular}{llll}
\hline Test & Result & Unit & Reference interval \\
\hline WBC & 2.8 & $\times 10^{3} / \mathrm{mm}^{3}$ & $4.1-10.1$ \\
RBC & 2.18 & $\times 10^{6} / \mathrm{mm}^{3}$ & $4.2-5.8$ \\
Hemoglobin & 6.6 & $\mathrm{~g} / \mathrm{dL}$ & $12-16$ \\
Hematocrit & 21.1 & $\%$ & $36-51$ \\
Platelet & 252 & $\times 10^{3} / \mathrm{mm}^{3}$ & $150-400$ \\
Na & 139 & $\mathrm{meq} / \mathrm{L}$ & $135-145$ \\
$\mathrm{~K}$ & 3.7 & $\mathrm{meq} / \mathrm{L}$ & $3.5-5.0$ \\
Blood glucose & 163 & $\mathrm{mg} / \mathrm{dL}$ & - \\
Urea & 87 & $\mathrm{mg} / \mathrm{dL}$ & $15-50$ \\
Creatinine & 1.8 & $\mathrm{mg} / \mathrm{dL}$ & $0.5-1.0$ \\
CRP & 47 & $\mathrm{mg} / \mathrm{L}$ & $<6.0$ \\
PT & 16.9 & $\mathrm{~S}$ & $11-15$ \\
Control & 12.2 & $\mathrm{~S}$ & - \\
INR & 1.38 & $\mathrm{~S}$ & $1-1.4$ \\
PTT & 32 & $\mathrm{~S}$ & $25-40$ \\
AST & 42 & $\mathrm{U} / \mathrm{L}$ & $<37$ \\
ALT & 45 & $\mathrm{U} / \mathrm{L}$ & $<41$ \\
ALP & 133 & $\mathrm{U} / \mathrm{L}$ & $70-306$ \\
LDH & 483 & $\mathrm{U} / \mathrm{L}$ & $<480$ \\
Amylase & 50 & $\mathrm{U} / \mathrm{L}$ & $<100$ \\
Lipase & 96 & $\mathrm{U} / \mathrm{L}$ & $\leq 60$ \\
\hline
\end{tabular}

bulk of the pathologic changes at the duodenum and severe duodenal wall edema also raised the possibility of primary duodenal pathology. Accordingly, a sign of ischemia was suggested, and a contrast-enhanced CT scan was advised to evaluate the related vessels further.

The patient remained hypotensive and oliguric regardless of intravenous fluid resuscitation. Nine hours after admission, norepinephrine was initiated. However, blood pressure remained low and fluctuated during the next five hours, with the minimum being $60 / 40 \mathrm{mmHg}$. Despite supportive treatment, the patient's condition deteriorated to the extent of severe electrolyte imbalance, gasping, severe acidosis (arterial $\mathrm{pH}=6.8$ ), and GCS 4/15. Due to the mentioned deterioration, another abdominopelvic $\mathrm{CT}$ scan with intravenous contrast was requested at the fourteenth hour of admission. The second CT scan demonstrated a marked decrease in the enhancement of the edematous duodenum and target sign. Since the related visible vessels were patent, microvascular ischemia or necrosis of the duodenum was highly suggested (Fig. 1).

The patient was immediately transferred to the operating room in a critical condition. With a midline laparotomy incision, $400 \mathrm{~mL}$ serous fluid was drained. Kocher's maneuver was performed to explore the duodenum and the retroperitoneal structures. Duodenum (D2-D3-D4) was grossly ischemic, the stomach was dilated, and the small bowel distal to the Treitz ligament appeared normal (Fig. 2). The Pancreas was normal in view, without any saponification, inflammation, or edema in favor of pancreatitis. Exploration of the superior mesenteric artery and vein did not reveal any pathologic findings. Whipple's procedure was planned initially. However, the patient's cardiac arrest during the operation directed the

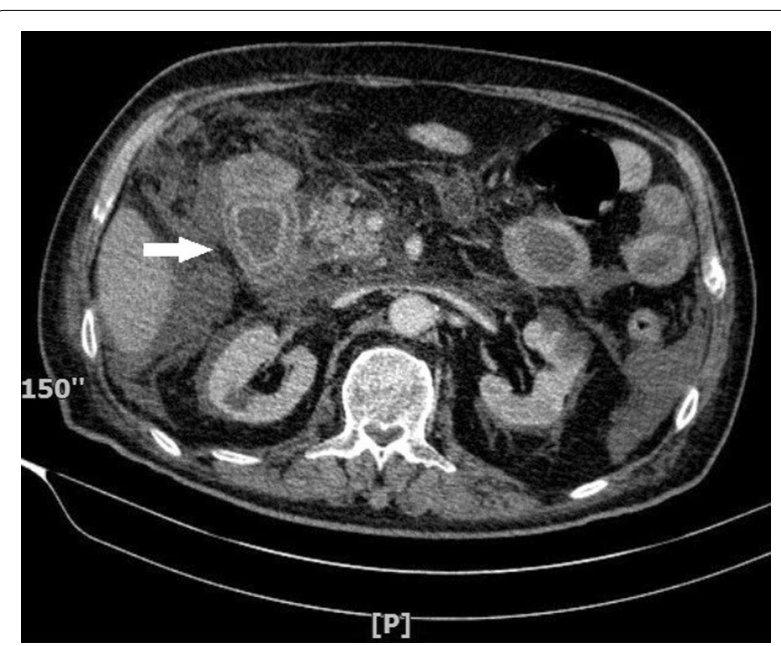

Fig. 1 Contrast-enhanced CT scan in favor of ischemic duodenum (white arrow) 


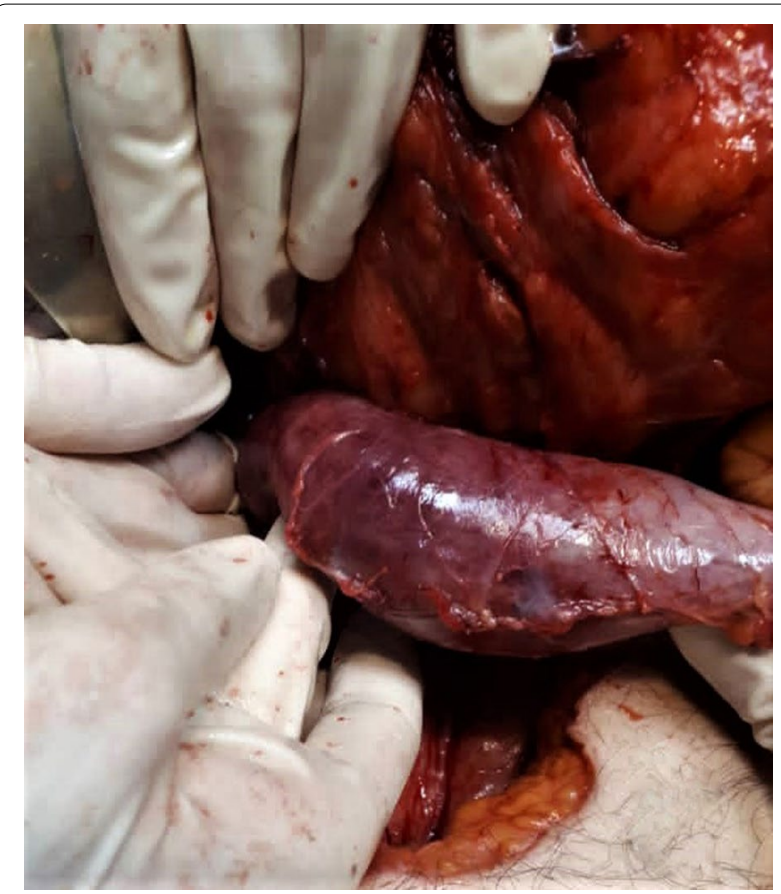

Fig. 2 Surgical exploration revealing ischemia of duodenum

plan to a damage control surgery. The overall operation time was approximately one hour and a half. To do the pyloric exclusion in the shortest time, the pylorus was isolated, and a polyester surgical tape was passed behind that. Tight ligation of the tape around the pylorus temporarily excluded the ischemic duodenum. To achieve a damage control surgery, decompression of the stomach was done by a red (18 French) nasogastric tube (Fig. 3). Lastly, an open (corrugated sheet) drain was placed near the duodenum, and the patient was then transferred to the intensive care unit. Despite two hours of supportive therapy, blood pressure remained $40 \mathrm{mmHg} /$ pulse, leading to a cardiac arrest with asystole rhythm and patient expiration. According to the refusal of next of kin to consent, an autopsy was not performed.

\section{Discussion}

Duodenal necrosis is a rare but lethal condition, with an almost $40 \%$ mortality rate [1]. With its rich blood supply, the incidence of isolated duodenal necrosis remains an enigma. The previously-explained etiologies of duodenal ischemia include pancreatitis [5, 6], vasculitis [2], caustic injury, trauma, Jejunal intussusception [1] or high loop obstruction [3], and perinephric abscess [7]. Nevertheless, the etiology remains unknown in some patients $[4,6]$, similar to the present case. There was no evidence of caustic injury or trauma in the history and physical examination of the patient. Additionally, the CT scan

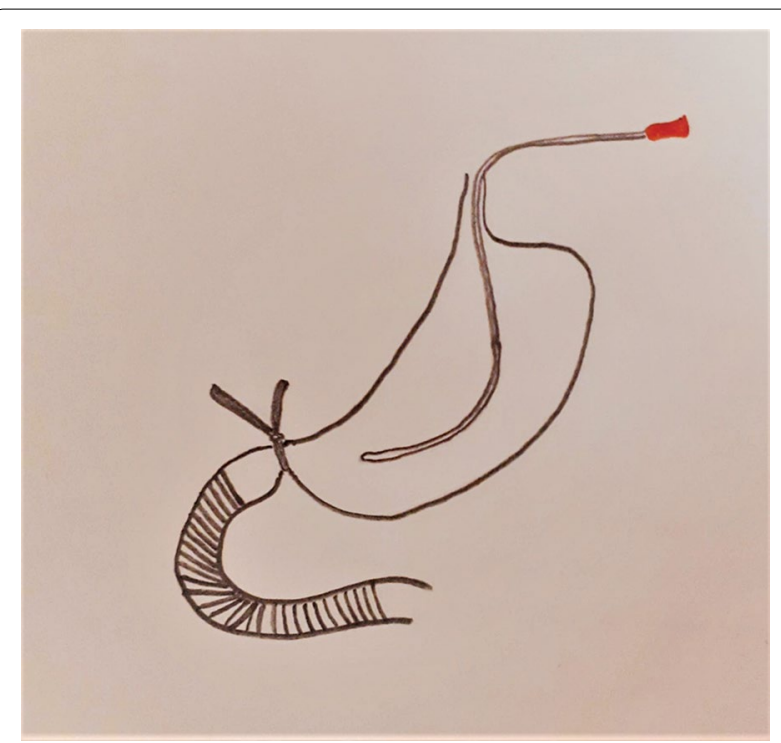

Fig. 3 Schematic picture of pyloric exclusion technique with polyester tape

and surgical exploration ruled out Jejunal obstruction, pancreatitis, perinephric abscess, and pathologies of the large vessels. Here we hypothesize other possible etiologies of duodenal ischemia in the present case.

The present case was complicated with myelodysplastic syndrome (MDS), a disorder with ineffective hematopoiesis and occasional coagulopathy. The MDS treatment regimen and the course of the disease might have contributed to duodenal ischemia in the present case.

With its anti-angiogenic potential, thalidomide could be suspected as an etiology of duodenal ischemia. Thromboembolic events (TEEs) are among the rare complications of thalidomide monotherapy. Occasional cases of TEEs with immunomodulatory drugs combined with anticoagulants are also reported [8-10]. As thalidomide and lenalidomide show almost similar rates of TEEs [11], we reviewed the literature for TEEs associated with any of the two mentioned immunomodulatory drugs (IMiDs). Deep vein thrombosis, pulmonary thromboembolism, myocardial infarction, and cerebrovascular accident are the expected forms of TEEs associated with IMiDs $[8,9,11]$. However, some unusual TEEs, including concurrent cerebrovascular accident and critical upper limb ischemia [12] and superior vena cava thrombosis [8] are also reported in the case reports of myeloma patients treated with thalidomide. Except for concomitant corticosteroid consumption in some of the mentioned cases $[9,12]$, no other risk factors for thrombosis were present. Whether the combination therapy of thalidomide and erythropoietin for the present case has been an 
additional risk of thrombosis is still controversial. Postmarketing analyses suggest an increased rate of TEEs in the combination therapy compared to the monotherapy [13]. However, the clinical trials do not confirm a significant difference [10, 14].

Vasculitis is another possible etiology for duodenal ischemia [2]. The prevalence of vasculitis in the MDS population is estimated at approximately 20\% [15]. MDS-associated vasculitis may not demonstrate the typical symptoms $[15,16]$ and worsens MDS prognosis $[15,17]$. Unusual TEEs have been observed in the setting of MDS in association with vasculitis. Incalzi et al. describe a case of central nervous system vasculitis in a patient with MDS, leading to diffuse ischemic damage of the central nervous system [18]. When common etiologies are ruled out, other ischemia of unknown etiology in patients with MDS (e.g., uterine [19] or splenic infarction [20]) could also be attributed to vasculitis [21-23]. The present case did not have symptoms or signs in favor of systemic vasculitis or involvement of any large abdominal vessels. However, isolated gastrointestinal vasculitis with medium or small vessel involvement is still a possible etiology of bowel ischemia in this patient. Segmental bowel ischemia is specifically expected when small vessels are involved. The challenging diagnosis and management of isolated gastrointestinal vasculitis pose the necessity of a medico-surgical interdisciplinary approach. As acute abdomen is the most common presentation of isolated gastrointestinal vasculitis, surgical resection and pathologic evaluation are the diagnostic and curative approaches for these cases. Immunosuppressive agents are the treatment of choice when the diagnosis is ascertainable before surgical intervention [24].

Whatever the etiology, duodenal ischemia requires emergent diagnosis and appropriate treatment. The CT scan findings in favor of duodenal necrosis include severe duodenal wall thickening and edema with water density of submucosa, which together create a target sign. Markedly reduced duodenal wall enhancement and significant stranding of the surrounding fatty tissue are other CT scan findings. Intestinal pneumatosis may also be visible in the advanced stages and is associated with an adverse prognosis [25]. When duodenal necrosis or peritonitis are suspected, surgical intervention may be mandatory. The surgical approach is dependent upon the site and size of the ischemia. The isolated ischemia or necrosis of D1 needs resection of the damaged part, and also end-toend anastomosis is acceptable. The involvement of D2 is a complicated feature that needs Whipple procedure or near-total duodenectomy [3]. The necrosis or ischemia of D3 or D4 can be managed by resecting the pathologic part and reconstruction with Roux-en-Y duodenojejunostomy or end-to-end duodenojejunal anastomosis [26].
Multidisciplinary discussion between the radiologist and the surgeon was among the strengths of this case management. There were also some limitations in the management of the present case. The rapid deterioration of the patient's condition limited the utilization of further tests to reveal the etiology of duodenal necrosis. There was also a delay in the diagnosis, mainly due to the patient's oliguria and the subsequent delay of contrast-enhanced CT scanning.

In conclusion, duodenal necrosis is a rare, fatal, and rapidly progressive condition that requires emergent intervention. Diagnosis is possible based on the CT scan findings, including significant reduction of the duodenal wall enhancement and the presence of duodenal wall edema and target sign. Surgery may be favored based on the patient's clinical condition, with its approach chosen according to the site of involvement.

\section{Abbreviations}

MDS: Myelodysplastic syndrome; CT: Computed tomography; TEEs: Thromboembolic events; IMiDs: Immunomodulatory drugs.

\section{Acknowledgements}

Not applicable.

\section{Authors' contributions}

NM and FS interpreted the patient's clinical data and planned the patient management. NM performed the operation. EM wrote the majority of the manuscript. All authors drafted, revised, and reviewed the final version of the manuscript. All authors read and approved the final manuscript.

\section{Funding}

None.

Availability of data and materials

All the relevant data have been provided in this published article.

\section{Declarations}

Ethics approval and consent to participate Not applicable.

\section{Consent for publication}

The written consent to publish images or other personal or clinical details was obtained from the patient's next of kin.

\section{Competing interests}

The authors declare no competing interests.

\section{Author details}

${ }^{1}$ Students' Scientific Research Center, Tehran University of Medical Sciences, Tehran, Iran. ${ }^{2}$ Department of Surgery, Imam Khomeini Hospital Complex, Tehran University of Medical Sciences, Tehran, Iran. ${ }^{3}$ Department of Radiology, Advanced Diagnostic and Interventional Radiology Research Center (ADIR), Tehran University of Medical Sciences, Tehran, Iran. ${ }^{4}$ Liver Transplantation Research Center, Imam-Khomeini Hospital, Tehran University of Medical Sciences (TUMS), Tehran, Iran.

Received: 22 October 2021 Accepted: 8 December 2021

Published online: 18 December 2021 


\section{References}

1. Karaisli S, Er A, Öirsel A, Kamer E. An extremely rare cause of acute abdomen. Turk J Gastroenterol. 2017:28(4):311-3.

2. Becker A, Mader R, Elias M, Lev A, Sayfan J. Duodenal necrosis as the presenting manifestation of polyarteritis nodosa. Clin Rheumatol. 2002;21(4):314-6.

3. Arcerito M, Margulies DR, Frykman PK. Duodenal necrosis secondary to a closed-loop bowel obstruction with novel reconstruction. J Pediatr Surg. 2012:47(2):394-6.

4. Gültekin FA, Tokgöz Ö, Çakmak GK, Taşçilar Ö, Cömert M. A rare cause of acute abdomen: idiopathic necrosis of the fourth part of the duodenum. Gazi Med J. 2012;23(1):29-32.

5. Takeyama Y, Ueda T, Hori Y, Shinkai M, Ajiki T, Kuroda Y. Duodenal necrosis associated with acute pancreatitis. Pancreas. 2001:22(2):217-9.

6. Żyluk A, Jagielski W, Piotuch B. Non-occlusive distal duodenal and proximal jejunal necrosis - a case report. Pomeranian J Life Sci. 2019;65(2):37-41.

7. Komoń M, Kutwin P, Kutwin L, Jabłonowski Z, Jabłoński S. Necrosis of the duodenal wall with retroperitoneal perforation as a complication of perirenal abcess. Case report and management. Polski przeglad chirurgiczny. 2019;92(3):51-4

8. Bowcock SJ, Rassam SMB, Ward SM, Turner JT, Laffan M. Thromboembolism in patients on thalidomide for myeloma. Hematology. 2002;7(1):51-3.

9. Scarpace $\mathrm{S}$, Hahn T, Roy H, Brown K, Paplham P, Chanan-Khan A, et al. Arterial thrombosis in four patients treated with thalidomide. Leuk Lymphoma. 2005:46(2):239-42.

10. Alkharabsheh OA, Saadeh SS, Zblewski DL, Gangat N, Begna KH, Elliott MA, et al. Frequency of venous thrombotic events in patients with myelodysplastic syndrome and $5 q$ deletion syndrome during lenalidomide therapy. Ann Hematol. 2019;98(2):331-7.

11. Li A, Wu Q, Warnick G, Li S, Libby EN, Garcia DA, et al. The incidence of thromboembolism for lenalidomide versus thalidomide in older patients with newly diagnosed multiple myeloma. Ann Hematol. 2020;99(1):121-6.

12. Ferri M, Faggioli G, Fratesi F, Stella A. Multifocal arterial thrombosis during thalidomide therapy: case report and review of the literature. Case Rep Med. 2009:2009:372073.

13. Yang $X$, Brandenburg NA, Freeman J, Salomon ML, Zeldis JB, Knight RD, et al. Venous thromboembolism in myelodysplastic syndrome patients receiving lenalidomide. Clin Drug Investig. 2009;29(3):161-71.

14. Toma A, Kosmider O, Chevret S, Delaunay J, Stamatoullas A, Rose C, et a. Lenalidomide with or without erythropoietin in transfusion-dependent erythropoiesis-stimulating agent-refractory lower-risk MDS without 5q deletion. Leukemia. 2016;30(4):897-905.

15. Belizna C, Subra JF, Henrion D, Ghali A, Renier G, Royer M, et al. Prognosis of vasculitis associated myelodysplasia. Autoimmun Rev. 2013;12(10):943-6.

16. Roupie AL, de Boysson H, Thietart S, Carrat F, Seguier J, Terriou L, et al. Giant-cell arteritis associated with myelodysplastic syndrome: French multicenter case control study and literature review. Autoimmun Rev. 2020;19(2):102446.

17. Arinobu Y, Kashiwado Y, Miyawaki K, Ayano M, Kimoto Y, Mitoma H, et al. Autoimmune manifestations associated with myelodysplastic syndrome predict a poor prognosis. Medicine. 2021;100(13):e25406.

18. Incalzi RA, Arena V, Capelli A, Gambassi G. Isolated PACNS-like presentation of a systemic vasculitis complicating a myelodysplastic syndrome. J Intern Med. 2004;255(6):674-9.

19. Melenhorst M, Hehenkamp W, de Heer K, Herger F. CT features in uterine necrosis of unknown cause: a case report. Clin Imaging. 2014;38(4):543-6.

20. Nalluru SS, Jindal V, Piranavan $P$, Kate $Y$, Siddiqui AD. Splenic infarction secondary to myelodysplastic syndrome: unravelling more etiologies. AME Case Rep. 2019:3:31.

21. Roma AA, Amador-Ortiz C, Liapis H. Significance of isolated vasculitis in the gynecological tract: what clinicians do with the pathologic diagnosis of vasculitis? Ann Diagn Pathol. 2014;18(4):199-202.

22. Hernández-Rodríguez J, Tan CD, Rodríguez ER, Hoffman GS. Gynecologic vasculitis: an analysis of 163 patients. Medicine. 2009;88(3):169-81.

23. Kabaoğlu B, Coşkun H, Yanar H, Karaarslan E, Yalti T. A rare case of splenic infarct presenting with acute abdominal pain due to polyarteritis nodosa: case report and review of the literature. Ulusal travma ve acil cerrahi dergisi = Turk J Trauma Emerg Surg. 2005;11(3):242-6.

24. Soowamber M, Weizman AV, Pagnoux C. Gastrointestinal aspects of vasculitides. Nat Rev Gastroenterol Hepatol. 2017;14(3):185-94

25. Moschetta M, Telegrafo M, Rella L, Stabile lanora AA, Angelelli G. Multidetector $C T$ features of acute intestinal ischemia and their prognostic correlations. World J Radiol. 2014;6(5):130-8.

26. Brunicardi FC. Schwartz's principles of surgery. 11th ed. New York: McGraw-Hill: 2019.

\section{Publisher's Note}

Springer Nature remains neutral with regard to jurisdictional claims in published maps and institutional affiliations.
Ready to submit your research? Choose BMC and benefit from:

- fast, convenient online submission

- thorough peer review by experienced researchers in your field

- rapid publication on acceptance

- support for research data, including large and complex data types

- gold Open Access which fosters wider collaboration and increased citations

- maximum visibility for your research: over 100M website views per year

At $B M C$, research is always in progress.

Learn more biomedcentral.com/submissions 